FedUni ResearchOnline

https://researchonline.federation.edu.au

This is the peer-reviewed version of the following article:

Coombs, N., Allen, L., Cooper, S., Cant, R., Beauchamp, A., Laszcyk, J.,...Peck, B. (2018) Exploring young Australian adult's asthma management to develop an educational video. Health Education Journal, 77(2), 179-189.

The online version of this article can be found at:

https://doi.org/10.1177/0017896917740721

Copyright ( IMechE 2013 Reprints and permissions: sagepub.co.uk/journalsPermissions.nav. 


\section{Exploring young Australian adults' asthma management to develop an educational video}

Short title: Young people's asthma management

\section{ABSTRACT}

\section{Objective}

This study explored young university students' (18-24 years) health literacy, asthma experiences and help-seeking behaviours to inform development of a web-based asthma education intervention relevant to this age group.

\section{Design}

An exploratory mixed methods design incorporated a health literacy survey and interviews, plus development of a web-based educational video.

\section{Setting}

Participants were students at two universities in Victoria, Australia

\section{Methods}

Twenty asthma sufferers were interviewed by trained university-student pairs. Interpretative phenomenology underpinned the narrative analysis and enabled description of the participant's lived experience. A branching e-simulation video was developed.

\section{Results}

Participants described 'Life with Asthma', including 'A life of vigilance' regarding asthma triggers, lifestyle limitations and heightened sensitivities; 'Asthma management - call Mum,' a lack of knowledge and support systems with substantial maternal reliance; 'Health literacy: family and Dr Google', low literacy levels with passive reluctant involvement in personal health management; and 'Information gathering - One size doesn't fit all' - a need for immediate gratification and resource variety. Based on interviewees' words and terminology, we designed an interactive branching educational video for YouTube portraying a young person (an actor) during an asthma flare up. 


\section{Conclusion}

Young adults lacked insight into their condition and even after moving away from home, relied on Google searches and/or parents' advice. To enhance health seeking behaviours, interactive programs with smart phone access are essential. Our open access program Help Trent Vent (https://www.youtube.com/watch?v=BhvLZCTy1jA) is a resource for young people with asthma as well as for health education teams, to reinforce asthma knowledge. 


\section{Manuscript}

\section{INTRODUCTION}

Asthma is a chronic disease of the airways which includes airflow obstruction leading to wheeze, cough and shortness of breath. Australia has one of the highest rates of asthma in the world and it is one of the most common problems treated by doctors (Australian Institute of Health and Welfare, 2005). The overall reported incidence of asthma in Victoria, Australia, in 2015 was $9 \%$ but is $11 \%$ within the 15-24 age group and $13 \%$ in regional areas (Australian Centre for Airway Disease Monitoring, 2016). Young adults with asthma have a higher risk of morbidity and mortality due to an increased likelihood that their asthma is poorly managed (Ellis, 2016) and prevalence does not appear to be declining, despite improved surveillance and enhanced medication protocols (Clearihan, 2016).

Inarguably, a pivotal period in the individual's asthma experience is the transition between paediatric and adult healthcare when young persons are expected to become independent with regard to their asthma management. A study that explored the barriers to effective asthma selfmanagement in adolescents in Florida by Panzera et al. (2013), identified that participants were likely to avoid asthma triggers (e.g. sport and outside activities), were reluctant to take (and often omitted) medications, and lacked understanding of their condition and its treatment.

These "cognitive and social skills which determine the motivation and ability of individuals to gain access to, understand and use information in ways which promote and maintain good health' as defined by the World Health Organisation are known as 'health literacy' (Nutbeam, 1998). Limited health literacy has been associated with poor asthma management (Brigham, 2016). Accordingly, education represents an important component for effective asthma management, with the need to develop programs that are tailored to age groups and levels of health literacy (Rosas-Salazar, 2012). Furthermore, there is a need to enhance the quality of health information that is accessible outside of a medical clinic (Fagnano, 2012). Thus, there is a need to better understand what it is like for young people to have a long-term condition, such as asthma and to provide contemporary education in a format that will be accessible and understood. 
This study aimed to explore young university students' health literacy, asthma experiences and help-seeking behaviours in order to understand their lived experience of asthma and to inform development of an interactive web-based asthma education intervention, specifically designed for the millennial learner.

\section{METHOD}

\section{Design}

An exploratory mixed methods design incorporated a quantitative health literacy survey and a descriptive qualitative (interview) approach (Cooper, 2007), aiming to discover how young people perceive the day-to-day experiences of living with asthma. In a second stage, the findings and student 'voices' would be used to inform development of an educational video script and subsequent filming of an educational video for young people, describing asthma management.

\section{Participants/Recruitment}

Interviewers: interprofessional student pairs

The researchers recruited and trained ten second-year undergraduate nursing students and nine second-year graduate-entry medical students $(n=19)$ from two universities to conduct the interviews as an interprofessional team of two. A web based and a two-hour face to face training program on in-depth interviewing were completed (program available on-line)(School of Nursing, 2016). The interview questions focussed upon asthma diagnosis, disease trajectory, medication management, and the student's support.

\section{Interviewees}

Volunteer young adults with asthma aged between 18-24 years were recruited from non-health related undergraduate degrees at the same two universities. Participants must have been medically diagnosed with asthma with experience of at least one acute asthma event. This was defined as acute breathlessness requiring an increase in medication; and/or significant reduction in activities of daily living; and/or seeking medical / assistance /attendance. Audiorecorded semi-structured interviews were held in a university room with a one-way viewing window, enabling an academic educator to observe and support the interviewing team (each team conducting two interviews). 


\section{Health literacy assessment}

Prior to interview, asthma participants completed four scales of the Health Literacy Questionnaire (HLQ). The HLQ is a multidimensional measure of health literacy that provides information on the health literacy competencies of individuals, and their lived experiences in attempting to engage with health and community service. The questionnaire has strong psychometric properties across nine separate scales, each shown to be independent, with each representing a different aspect of health literacy, and can therefore be treated as independent scales (Osborne, 2013). The four HLQ scales used for this study were chosen due to their research relevance and included: Scale 1. 'Feeling understood and supported by healthcare providers'; Scale 2. 'Having sufficient information to manage my health'; Scale 3. 'Actively managing my health'; and Scale 4. 'Social support for health'.

\section{Data analysis}

The interviewers were not involved in the data analysis, however the audio-recorded interviews collected by them were transcribed verbatim by a commercial provider. Based on phenomenology, an inductive approach to analysis was taken including data reduction and display, development of a coding framework, and identification and refinement of themes as described by Attride-Stirling (2001) and informed by Cresswell (2003). At each stage of data analysis the emergent themes and their descriptors were cross checked through disussion between members of the research team to achieve consensus.

HLQ scale scores were collated and are presented as means and 95\% confidence intervals (CI). Participants with mean scale scores of $<3.00$ were considered to disagree or strongly disagree with the concept measured by that scale, and these results are reported as proportions.

\section{Ethics}

Ethical approval for the study was obtained from the respective Human Research Committees (removed for review CF15/4250 - 2015001822; removed for review A15-166).

\section{RESULTS}

\section{Interview participants with asthma}

Nineteen students with asthma aged between 18 and 25 attended individual face-to-face interviews and one was interviewed by telephone $(n=20)$. The students were enrolled in a range of bachelor degrees, such as education and arts. Most were female $(n=13)$ and had received an 
asthma diagnosis by the end of elementary (primary) school $(n=16)$, or in their teenage years $(n=3)$. Eleven reported having had no recent attacks, seven reported between one and three attacks, and two reported six and 13 attacks. With regard to asthma severity, two maintained daily or twice daily preventive medication (a nebuliser) while the remainder used a salbutamol (Ventolin) puffer only when symptomatic.

\section{Life with Asthma}

An overarching view of 'Life with Asthma' was described, and emergent sub themes were: 'A life of vigilance'; 'Asthma management - call Mum'; 'Health literacy - family and 'Dr Google'; 'Information gathering- one size doesn't fit all'.

Table 1 presents key student quotations, selected to represent students' voices. These are identified by a participant number e.g. (P17). Further explanation of each subtheme is seen below.

\section{INSERT Table 1 about here}

\section{Table 1:}

Qualitative analysis of asthma students' narratives- subthemes and exemplar quotations

\begin{tabular}{|c|c|}
\hline KEY THEME & Exemplar student quotations \\
\hline \multirow[t]{6}{*}{ A life of vigilance } & $\begin{array}{l}\text { I get tightness in my chest. And then, you're really deep breathing, and you're } \\
\text { struggling to get breath. (P13). }\end{array}$ \\
\hline & $\begin{array}{l}\text {...if I do end up running, I have difficulty breathing. But it's also now } \\
\text { triggered by a lot of dust, or allergies. Yeah, there's a few different things that } \\
\text { bring it on. (P2) }\end{array}$ \\
\hline & It's weird because sometimes it's worst at night - like in the evening. (P12) \\
\hline & $\begin{array}{l}\text { You can't really help changing weather. Really, I just stay warm, nothing } \\
\text { [else] really (P4) }\end{array}$ \\
\hline & $\begin{array}{l}\text {... sometimes my preventer won't do enough and I will feel a bit short of } \\
\text { breath and tight in the chest and have to take Ventolin [Salbutamol] as well. } \\
\text { (P17) }\end{array}$ \\
\hline & $\begin{array}{l}\ldots \text { it's just so uncomfortable. Like you can't - unless you're actually asthmatic } \\
\text { it's hard to understand (P7) }\end{array}$ \\
\hline
\end{tabular}

Asthma management - call Mum
[I'm] pretty confident. I've had it [asthma] for quite a while, so I know what to do and I know what to do it with. (P20)

I really get mum to manage it for me... I go 'mum, do I take my inhaler now?' 'Yeah, take your inhaler now.'... Because well mum is the only one that's really got experience with this so no one else really knows what to do. (P9) 
I'd still ring mum because she's five minutes down the road..... I always just ring mum. Yeah, well she knows what's going on. Dad forgets. (P11)

Usually yeah, if I'm at home or something I call Mum [who is a nurse] ... and she'll be like "calm down and have you taken this, have you done this?" (P13)

...if it [asthma] was that bad then I'd just freak out and go to the doctors, or the hospital, or whatever. I don't know. No, I don't have one [an action plan]. (P8)

It would be mum, and then I'd see what she says. (P14)

Health literacy: Google' family and ' $\mathrm{Dr}$

Mum was a nurse, so she was trained in that sort of stuff. So, I just listened to whatever my mum had to say. (P2)

My brother, he got a lot of information and stuff and when I was a kid .... so I just read it all. ... Yes, and mum had it all over the fridge. (P4)

... especially for my triathlons and things ...I do try and learn, myself, the best ways [to manage asthma]. (P6)

Well, I don't take my preventer like I'm supposed to. I just forget. I know how to do it, I'm just not the best with it. (P15)

I don't know much at all about it [asthma], to be honest. ...I don't want to know, in a way. (P8)

Information gathering- one size doesn't fit all

Reading facts, and triggers, and things like that, would be cool. Even just simple things of how much is too much of your puffer? (P17)
I feel I'm a very visual learner. So things like images, videos, would definitely work for me. But I guess text would also work. I just feel like those [visuals] would be a lot easier to understand. (P2)

Well just because younger generations these days are more interested in their electronics. Just like a game that's more information about it. So like a person have an asthma attack and goes what would you do? (P9)

Especially if you sign up for, like a website or Facebook, then you'll get regular things. And then also you can click on that, and get all your further information. (P15)

Maybe, the fact sheets. ... I don't really watch videos unless they're short. (P4)

....this is what someone who's having an asthma attack looks like, this is what you do when you see this happen. Even something like that, so if they see you out in the public and saw it, they would be able to recognise it and call an ambulance. (P14)

\section{A Life of Vigilance}

All participants described asthma as a way of life that required a new and heightened level of vigilance. This sub-theme captures the new found need for these young people to be vigilant 
regarding elements of every-day life that others may take for granted. Participants viewed the main triggers for an attack as a sudden change in air temperature (e.g. to night-time cold), house or farm dust, pollen, a chest infection, and sport or exercise. As well as environmental triggers participants also described a heightened sensitivity to their own physiological responses, describing their main asthma symptoms in similar ways.

Many of the participants described sports such as netball or football as key sources of social engagement in their rural communities, and frustration that asthma imposed restrictions upon their participation. Some students felt that having asthma was an unwelcome imposition that marked them out as different from their peers. Hence, in this sub-theme students described asthma as a burden impacting everyday life and demanding heightened vigilance in many activities.

\section{Asthma Management - 'Call Mum'}

It emerged that no participant had required hospitalisation for asthma in the previous 12 months, having successfully managed any asthma attack. Further, the majority of participants did not take 'preventer' medication and responded to asthma flare ups with inhaled reliever medication from a puffer (e.g. salbutamol). Some felt entirely confident with management while others relied on others for advice during an attack. While most had had a formal written asthma management plan during their early school years, these were now expired. The only student who had an active asthma plan was confident of managing an attack.

In terms of managing asthma attacks most based their treatment on personal tried and tested practices. In instances where an exacerbation of asthma symptoms arose that required some form of management, participants described taking action I try and get on it as soon as I can. ... (P7) to sit down/rest to avoid escalation into an attack. The majority of participants identified with either not knowing what to do and not seeking emergency third-party professional help, or contacting their mother or a family member for direction about how to manage an asthmaevent. Coincidentally, it was discovered that several of the participants had mothers or parents who were medically trained; ie: were nurses, or had family members who were asthma suffers themselves and therefore reliance on their support was evident in the participant responses.

Few students perceived that they might need to call for assistance from an ambulance service and no student thought they would call the university health clinic, often unaware that the 
service was available. Thus, this subtheme describes a spectrum of health care behaviours around self-managing asthma.

\section{Health Literacy: Family and Dr Google}

Students relied heavily on the information that they had received upon their initial diagnosis, with continued reliance upon family member/s for advice and support. There was little evidence of intent to actively seek out contemporary information with many suggesting that they had learned about it ' $a$ s a kid'. Very few were aware of the national body for asthma - the National Asthma Council Australia, and it's website. When information was sought, the main external sources were the family GP, general Internet searches using Google ("Dr Google"), an Australian asthma website, and pamphlets/fact sheets obtained from a clinic and from pharmacies. Several students did not prioritise their asthma care or seek out asthma information and were occasionally in denial of their condition, not taking medication.

This theme suggests that whilst information pertaining to asthma care is readily available from many sources, young people are not sufficiently engaged in seeking contemporary evidence or advice.

\section{Information Gathering: One Size Doesn't Fit All}

When participants were asked about a preferred framework and mode of delivery for asthma information, it was clear that one approach alone is not ideal. Online information accessible by phone or computer were, however, regarded as essential.

A variety of educational formats such as video, text, case studies or blogs were suggested to cater for different learning styles. Some participants felt they would not have time to read a blog, and others indicated that they would download and use an app. Overall there were diverse views regarding the best format for online resources. It was clear however, that brief and easyto-understand text/video/pictorial resources would be most acceptable to this age group.

Despite adult perceptions of young peoples' preferences for health-related information, this subtheme problematizes the one size fits all approach, and opens up opportunities for further innovation.

\section{Results of HLQ questionnaire}


The interview findings were supported in the results of four HLQ scales. The scales with the highest proportions of participants who, on average, disagreed or strongly disagreed with the concept were Scale 2 and Scale 3 (Table 2). One-third of participants disagreed or strongly disagreed that they had 'Sufficient information to manage my health' and disagreed or strongly disagreed that they 'Actively manage my health'.

Alternatively, participants were more positive about Scale 1: 'Feeling understood and supported by healthcare providers', as $84 \%$ agreed and $16 \%$ disagreed or strongly disagreed that they had an established relationship with at least one healthcare provider who knew them well and who they trusted to provide useful advice. For Scale 4: 'Social support for health', all participants agreed or strongly agreed that their social system provided them with all the support they wanted, or needed, for their health. Interview findings indicate that this support comes from team mates, friends and family, but most significantly, from their mothers.

\section{INSERT Table 2 about here}

\section{Table 2:}

HLQ scale scores and proportions of participants who disagreed or strongly disagreed with each scale

$\begin{array}{ll}\text { HLQ scale } & \begin{array}{l}\text { Mean scale score } \\ (95 \% \mathrm{CI})\end{array} \\ & \begin{array}{l}\text { Proportion who, on } \\ \text { average, disagreed or } \\ \text { strongly disagreed }\end{array}\end{array}$

Scale 1. Feeling understood and supported by healthcare providers

$3.17(2.94,3.40) \quad 16 \%$

Scale 2. Having sufficient information to manage my health

Scale 3. Actively managing my health $32 \%$

Scale 4. Social support for health

$0 \%$

Abbreviations: $C I=$ confidence interval. Disagree or strongly disagree defined as having mean scale score of $<3.00$.

\section{Development of web-based educational video}


The findings were used to develop an asthma education intervention relevant to young asthma suffers. It was clear that asthma participants were digital savvy and utilized smart phones or other devices to download apps: the millennial generation (Considine, 2009). Based on the findings we used the words and terminology of interviewees to design an interactive e-simulation (Cant, 2014) film for YouTube that portrays a young person (an actor) developing an asthma flare up. Clinically-qualified team members contributed, reviewed, and approved the scripted material showing the use of asthma medication.

Students learn best through experience. The simulated asthma event portrayed by the actor is the artificial representation of a complex real-world process with sufficient fidelity (believability) to facilitate learning - but without the risks inherent in a real-life experience. Materials were based on Kolb's theories of experiential learning (Kolb, 1984) enabling viewers to gain concrete experience (seeing a person having an asthma episode), use reflective observation (reflect on the decisions they make in regards to actions they take) abstract conceptualization (analysing the impact their decision has on the patient and their condition), and active experimentation (apply learnt outcomes for further decisions made throughout the scenario).

Insert figure 1: Kolb's experiential Learning Cycle

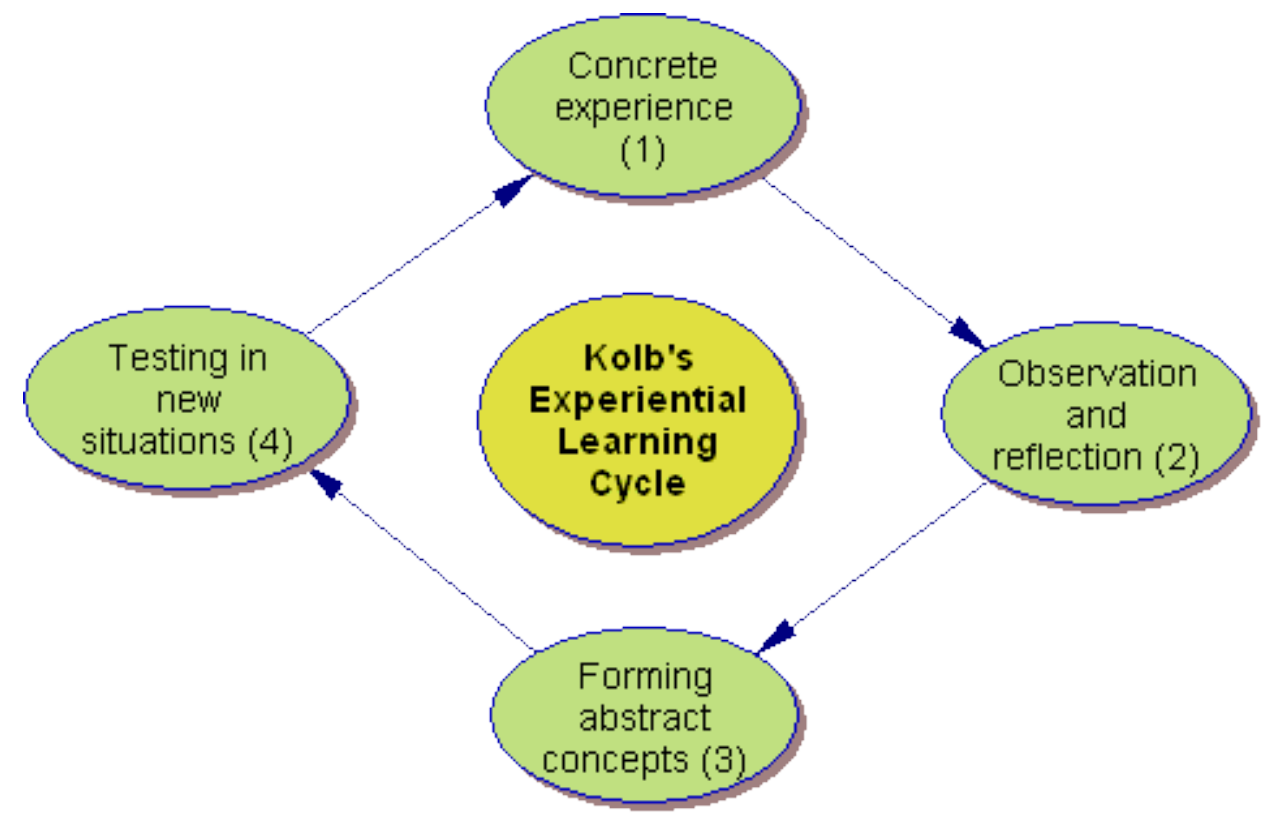

https://www.learning-theories.com/experiential-learning-kolb.html

The film utilizes a branched-narrative simulation (such as is used in the health education field) (University of Pittsburgh, 2017) based on presenting a challenge, offering the learner choices 
and with a consequence based on the specific choices. This brings the learner into the scenario, allowing them to discover more. The decision pathways were programmed to enable the viewer to select an action e.g. the 'best' method of inhaler use, or calling an ambulance, or their mothers. Depending on the decisions made, the actor improves, or continues to deteriorate. In line with participant preferences, the video is short with a duration of 3 mins.

The film named Help Trent Vent is publicly available on YouTube at: https://www.youtube.com/watch?v=BhvLZCTyljA

INSERT Figure 2- Screen shot- Help Trent vent

\section{DISCUSSION}

This study sought to explore the day-to-day experiences of young people living with asthma and describes their self-care behaviours in relation to asthma experiences, management and health literacy. It is evident from the findings that participants had a varied and often poor understanding of their condition, with little understanding of how to independently manage acute flare-ups. One explanation for this relates to documented lower levels of health literacy, as one third of participants reported that they did not have all the information that they needed to manage their condition. Of note, national guidelines recommend the use of daily preventive anti-inflammatory medications for all children and adults with persistent asthma (National Asthma Education and Prevention Program, 2007). There was low compliance in the current study with most participants taking medications only when symptomatic. Halterman et al. (2011) report that whilst there has been a significant effort in improving paediatric asthma care, there has been insufficient provision of education to adolescents regarding promotion of medication adherence and ongoing asthma care. Our new video education intervention may help to fill this gap by demonstrating the importance of effective self-management.

Although participants had learned how to manage their asthma from a parent or doctor when they were younger, asthma management plans were no longer used and participants did not appear to graduate to any form of adult independent health seeking behaviours. Despite living autonomously out of home or at university, many participants were still relying on adult guidance with resultant uncertainty about their ability to self-manage their condition. One-third 
of participants reported that they were not proactive in managing their health, yet all reported strong social support for health, suggesting a reliance on others. Milnes and McGowen et al. (2013) who explored young peoples' compliance with asthma health reviews, describe failures to take personal responsibility for health as being related to the dominance of parental management and the lack of confidence/skill young people have in communicating their health concerns. The authors suggested young people's self-efficacy can be increased through observing how peers perform, which confirms our choice of educational strategy through video portrayal of a peer story. Filming of real people, used to simulate behaviour and changes in health outcomes, has been seen to be a more effective teaching tool for potential changes in patients' behaviour. For example, a recent systematic review by Abed et al (2014) identified 20 RCTs of video based educational programs. A significant effect was identified in 13 studies of which 10 identified a change in health related outcomes. This education method has produced more positive outcomes in behaviour change than that of didactic or graphical use of video technology, and thus was the option chosen for delivery of this asthma education information.

Motivation for health independence appears to be low when considering the comments made in relation to the need for quick and easy access to information, with participants only seeking advice if their medication was not effective or their condition deteriorated. Our findings in relation to choice and forms of information align with the recent findings of Coyne, Prizeman et al. (2016) who conducted a mixed methods study to identify the information needs of adolescents and young adults with long term illnesses as they transition to adult healthcare. Adolescents expressed preference for health information that was online, trustworthy, nonpatronising and empowering, with information about medications and the differences between child and adult healthcare, plus testimonials. This resulted in the website 'Stepping Up' (www.SteppingUP.ie) hosted by Trinity College, Dublin. Contemporary video production methods now enable the production of practical and narrative formats with interactive decision pathways which strengthens the video education approach further. This was the approach we took with the aim of improving 1 . The skills required for inhaler use and self-management, and 2. Applicable health seeking behaviours and recognition of deterioration or crisis. Currently the video is available through You Tube with planned additional active implementation through a health practitioners 'patient deterioration management program' known as First2ActWeb. 
Although many participants in the current study stated they felt 'in control' of their asthma, many admitted that they did not comply with their medication regimes and there was a lack of understanding of what to do in an emergency. Concerns were also raised about how their condition was accepted by peers as they did not want to be labelled with their condition, or be seen to be incapacitated in any way. In general, they saw their condition as inconvenient and embarrassing with unpleasant medication side effects, all of which relate to personal identity versus role confusion during the transition to adulthood (McLeod, 2013). Other authors also identified that adolescents are ashamed of their asthma condition (Heyduck, 2015). Such perspectives underline the need for strong relationships and emotional support for young people with asthma to ensure maintenance of self-esteem during transitions to adulthood.

\section{Limitations}

This study focused on one population in one state of Australia. Although thematic saturation was achieved in 20 interviews, as a descriptive study the findings cannot be considered generalisable to other populations. Despite this, there may be similarities in the understandings and experiences of young adults elsewhere. Further, although the student interviews were monitored by researchers, it is possible that the interview process may have lacked deep exploration of some of the issues concerning young people. The small sample size and the decision to use only some of the available scales from the HLQ, also limits the exploration of literacy within this participant group.

\section{CONCLUSION}

Young adults in this study felt limited by asthma and lacked insight into their condition, relying heavily on Google searches for medication information and on their mother's advice, even after

moving away from home. In order for them to better engage with their health condition and to enhance health literacy and applicable health seeking behaviours, interactive educational programs with smart phone access are essential for this age group. Based on participants' information preferences a YouTube film was developed as an educational tool for young people with asthma. (see: Help Trent Vent at: https://www.youtube.com/watch?v=BhvLZCTy1jA) This portrays a young person (an actor) developing an asthma flare up, and is openly available online as a resource for young people with asthma as well as for health education teams, to reinforce asthma knowledge. 


\section{References}

Abed MA Himmel W Vormfelde S and Koschack J (2014) Video-assisted patient education to modify behavior: A systematic review. Patient education and counseling, 97:1 16-22.

Attride-Stirling J (2001) Thematic networks: an analytic tool for qualitative research.

Qualitative Research, 1, 385-405. doi/pdf/310.1177/146879410100100307

Australian Centre for Airway Disease Monitoring (2016) The use of lung function testing for the diagnosis and management of chronic airways disease: demonstration data linkage project using the 45 and Up Study 2001-2014. Australian Centre for Airway Disease Monitoring. Available at: http://www.asthmamonitoring.org/ (accessed March 2, 2016).

Australian Institute of Health and Welfare (2005) Chronic respiratory diseases in Australia: Their prevalence, consequences and prevention. Canberra, Australian Institute of Health and Welfare, AIHW Cat. No. PHE 63.

Brigham E Goldenberg L Stolfi A, et al. (2016) Associations between parental health literacy, use of asthma management plans, and child's asthma control. Clinical Pediatrics 55: 111117. DOI: $110.1177 / 0009922815587089$

Cant R and Cooper SJ (2014) Simulation in the Internet Age: The place of Web-based simulation in nursing education. An integrative review. Nurse Education Today 34: 14351442. doi: 1410.1016/j.nedt.2014.1408.1001

Clearihan L (2016) The asthma enigma -How are we doing 25 years on? Australian Family Physician 45: 9.

Considine D Horton J and Moorman G (2009) Teaching and reaching the millennial generation through media literacy. Journal of Adolescent \& Adult Literacy 52: 6. doi:10.1598/JAAL.1552.1596.1592

Cooper S and Endacott R (2007) Generic qualitative research: A design for qualitative research in emergency care? Emergency Medicine Journal 24: 816-819. doi:810.1136/emj.2007.050641 
Coyne I Prizeman G Sheehan A, et al. (2016) An e-health intervention to support the transition of young people with long term illnesses to adult healthcare services: Design and early use. Patient Education and Counselling 99: 1496-1504.

Creswell J (2003) Research Design, Qualitative, Quantitative and Mixed Methods Approaches. Thousand Oaks, CA, Sage Publications.

Ellis D King P and Naar-King S (2016) Mediators of treatment effects in a randomised clinical trial of multisystemic therapy-health care in adolescents with poorly controlled asthma: disease knowledge and device use skills. Journal of Paediatric Psychology 1: 522530. Doi: 510.1093/jpegsy/jsv1114

Fagnano M Halterman JS Conn KM, et al. (2012) Health literacy and sources of health information for caregivers of urban children with asthma. Clinical Pediatrics 51: 267-273.

Halterman J Riekert K Bayer A, et al. (2011) A pilot study to enhance preventative asthma care among urban adolescents with asthma. Journal of Asthma 48: 523-530. DOI: $510.3109 / 02770903.02772011 .02576741$

Heyduck K Bengel J Farin-Glattacker E, et al. (2015) Adolescent and parental perceptions about asthma and asthma management: a dyadic qualitative analysis. Child: Care, Health and Development 41: 1227-1237. DOI: 1210.1111/cch.12277

Kolb DA (1984) Experiential learning: Experience as the source of learning and development. Englewood Cliffs NJ: Prentice-Hall.

McLeod S (2013) Erik Erikson; Stage 5: Retrieved from www.simplypsychology.org/ErikErikson.htmlSimplyPsychology. (accessed September 28, 2016).

Milnes L McGowan L Cambell M, et al. (2013) A qualitative evaluation of a pre-consultation guide intended to promote the participation of young people in asthma review consultations. Patient Education and Counselling 91: 91-96.

National Asthma Education and Prevention Program (2007) Expert panel report III: guidelines for the diagnosis and management of asthma. Bethesda, MD, National Institute of Health, National Heart, Lung, and Blood Institute, 2007. Publication No. 07-4051.

Nutbeam D (1998) Health Promotion Glossary. Heath Promotion International 13: 349-364. 
Osborne R Batterham RW Elsworth GR, et al. (2013) The grounded psychometric development and initial validation of the Health Literacy Questionnaire (HLQ). BMC Public Health 13. doi: 10.1186/1471-2458-1113-1658

Panzera A Schneider TK Martinasek MP, et al (2013) Adolescent asthma self-management: Patient and parent-caregiver perspectives on using social media to improve care. Journal of School Health 83: 921-930.

Primary Healthcare Network Gippsland (2014) Brief Population Health Snapshot (using Victorian Public Health Survey 2011-12). Available at: http://www.gphn.org.au/wpcontent/uploads/2014/02/Brief-Population-Health-Profile-Gippsland-Snapshot-2016-FINALfor-Web.pdf (Accessed August 8, 2015).

Rosas-Salazar C Apter AJ Canino G, et al. (2012) Health literacy and asthma. Journal of Allergy and Clinical Immunology 129: 935-942.

School of Nursing, Midwifery and Healthcare (2016) How to perform a research interview. Available at: http://federation.edu.au/faculties-and-schools/faculty-of-health/studentresources/clinical-education/help-seeking-behaviour-asthma-project (accessed 10th December 2016).

University of Pittsburgh. 2017. vpSim- Virtual patient simulation. [online] The Laboratory for Educational Technology at the University of Pittsburgh School of Medicine. Available at: https://let.pitt.edu/?page_id=32. [Accessed 20 $0^{\text {th }}$ June 2017]. 